OPEN ACCESS

Edited by:

Alessia Libera Gazzonis,

University of Milan, Italy

Reviewed by:

Paolo Merella

University of Sassari, Italy

Perla Tedesco,

University of Bologna, Italy

*Correspondence:

Xiaohui $A$

aixh@yfi.ac.cn

Specialty section:

This article was submitted to

Parasitology,

a section of the journal

Frontiers in Veterinary Science

Received: 07 February 2021

Accepted: 11 March 2021

Published: 06 April 2021

Citation:

Zhou S, Dong J, Liu Y, Yang Q, Xu N, Yang $Y$ and Ai $X$ (2021) Antiparasitic Efficacy of Herbal Extracts and Active Compound Against Gyrodactylus kobayashii in Carassius auratus.

Front. Vet. Sci. 8:665072.

doi: 10.3389/fvets.2021.665072

\section{Antiparasitic Efficacy of Herbal Extracts and Active Compound Against Gyrodactylus kobayashii in Carassius auratus}

\author{
Shun Zhou ${ }^{1,2}$, Jing Dong ${ }^{1,2}$, Yongtao Liu ${ }^{1,2}$, Qiuhong Yang ${ }^{1,2}$, Ning $X u^{1,2}$, Yibin Yang ${ }^{1,2}$ and \\ Xiaohui $A i^{1,2 *}$ \\ ${ }^{1}$ Yangtze River Fisheries Research Institute, Chinese Academy of Fishery Sciences, Wuhan, China, ${ }^{2} \mathrm{Hu}$ Bei Province \\ Engineering and Technology Research Center of Aquatic Product Quality and Safety, Wuhan, China
}

Gyrodactylus spp. Nordmann, 1832 (Monogenea: Gyrodactylidae) are common ectoparasites of teleost fishes. Infection with these parasites can increase the mortality of fish and cause considerable economic losses in intensive aquaculture. To find an effective antiparasitic agent for the control of gyrodactylosis, antiparasitic efficacy of crude extracts of 36 herbal medicines was evaluated using a Carassius auratus (Cypriniformes, Cyprinidae)-Gyrodactylus kobayashii model. Among all tested medicines, methanol extract of Dioscorea collettii var. hypoglauca (Dioscoreales, Dioscoreaceae) was the most efficient, with an $\mathrm{EC}_{50}$ value of $4.17 \mathrm{mg} / \mathrm{L}$. This extract showed $100 \%$ antiparasitic efficacy against $G$. kobayashii at $10 \mathrm{mg} / \mathrm{L}$ and had a therapeutic index ( $T I, L_{50} / E_{50}$ ) of 5.26 , which is higher than that of formaldehyde $(\mathrm{TI}=4.58)$, a widely used parasiticide in aquaculture. Subsequently, the potential mechanism of antiparasitic activity of dioscin, an active compound isolated from $D$. collettii var. hypoglauca was investigated and the histopathological alterations in goldfish after exposure to dioscin were also studied. The in vivo trial indicated dioscin showed significant antiparasitic activity with a $24 \mathrm{~h}-\mathrm{EC}_{50}$ value of $1.58 \mathrm{mg} / \mathrm{L}$ and it exhibited $100 \%$ antiparasitic efficacy at $0.6 \mathrm{mg} / \mathrm{L}$. Also, G. kobayashii could be completely removed in vivo within $2 \mathrm{~h}$ at $0.6 \mathrm{mg} / \mathrm{L}$ dioscin. Whereas, mean survival time of this worm in vitro was $4.99 \mathrm{~h}$, and some individuals even reached $12 \mathrm{~h}$ at the same concentration of dioscin. These results indicated that $0.6 \mathrm{mg} / \mathrm{L}$ of dioscin did not completely kill all worms within $2 \mathrm{~h}$, but just temporarily remove the worms from goldfish. Scanning electron microscopy (SEM) analysis showed that most of the microvilli on the tegument surface of $G$. kobayashii dropped after exposure to dioscin. This might be one of the potential mechanisms of antiparasitic activity of dioscin against G. kobayashii. Furthermore, no severe histopathological alteration was observed after exposure to a high concentration of dioscin for a short time. Considering both effectiveness and safety, therapeutic baths with a high concentration of dioscin for a short time might be a more optimal choice for the treatment of gyrodactylosis in aquaculture.

Keywords: antiparasitic activity, herbal medicine, dioscin, Gyrodactylus kobayashii, Dioscorea collettii var. hypoglauca 


\section{INTRODUCTION}

Gyrodactylus spp. Nordmann, 1832 (Monogenea: Gyrodactylidae) are common flatworm ectoparasites of teleost fishes, which received an ample amount of scientific attention for their ability to cause a sharp drop in the production of salmonids and other freshwater fish $(1,2)$. They have a direct life-cycle and several generations occur within an individual parasite. New-born flatworms are capable of directly infecting the primary host $(3,4)$. These parasites can infect entire fish stocks and reach high infection intensities rapidly because of their high transmission rate and short generation time (5). Gyrodactylids attach to the host's epithelium through sclerotized hooks and feed on mucus and epithelial cells, resulting in damage to the fish tissue (2). The damage of the epidermis facilitates the invasion of secondary infections with other pathogens, which can increase the mortality of fish and then cause considerable economic losses due to epidemics in intensive aquaculture $(2,6)$.

To control gyrodactylosis in aquaculture, several chemical substances, including mebendazole, formalin, hydrogen peroxide and praziquantel, have been widely used (7-10). However, frequent use of these chemical substances results in the development of resistance to drugs, environmental contamination, as well as risks to human health $(11,12)$. It is thus necessary to find alternative and effective therapeutics to treat gyrodactylosis. Herbal medicines have been considered as alternative options due to their biodegradability and environmental friendliness (13). A previous study indicated that methanol extract of Paris polyphylla (Liliales, Melanthiaceae) is an effective alternative agent to control gyrodactylid infections, but its feasibility in the practical application has been largely restricted due to its high price (14). The saponins are believed to be the main active components of $P$. polyphylla, and previous studies and unpublished data also indicated that some saponins, such as gracillin, are effective against gyrodactylosis $(14,15)$. Saponins are structurally and biologically diverse phytochemicals that are widely occurring in many plants from the families Dioscoreaceae, Liliaceae, Solanaceae, Asclepiadaceae, etc. (16). Therefore, screening an effective and inexpensive agent from herbal medicines containing saponins may be a promising research direction.

The dried rhizome of Dioscorea collettii var. hypoglauca (Dioscoreales, Dioscoreaceae) is a traditional Chinese medicine widely used for the treatment of cervical carcinoma, carcinoma of the bladder and renal tumor (17). Previous researches indicated that ethanol extract of $D$. collettii var. hypoglauca and its active ingredients induced morphological abnormality of Pyricularia oryzae (Magnaporthales, Magnaporthaceae) and displayed cytotoxicity to cancer cells $(18,19)$. However, antiparasitic activity of $D$. collettii var. hypoglauca has not yet been reported up to now. Also, the analysis of the chemical constituents showed that the content of dioscin in the D. collettii var. hypoglauca was higher and dioscin has been proved to show good antiparasitic activity against G. kobayashii $(14,20)$. However, the antiparasitic mechanism of this compound has not been studied. Solanum nigrum (Solanales, Solanaceae) is a member of the Solanaceae family that has been widely used in traditional Chinese medicine (17). It has been found that S. nigrum contains steroid alkaloids, steroidal saponins and flavonoids, etc., which may be responsible for a broad spectrum of pharmacological activities (21). For example, Pestana et al. (22) found that acetone extract of S. nigrum showed $100 \%$ nematocidal activity against Pratylenchus goodeyi (Tylenchida, Pratylenchidae) after 23-h exposure. Also, crude aqueous extracts of S. nigrum displayed evident antiparasitic activity against the larva of Fasciola hepatica (Plagiorchiida, Fasciolidae) (23). However, to the best of our knowledge, antiparasitic activity of S. nigrum against fish monogeneans has not been reported so far.

To find an effective agent for the treatment of gyrodactylosis, in the current study, 36 herbal medicines were obtained and antiparasitic efficacy of their crude extracts was evaluated. Two kinds of herbal medicines (D. collettii var. hypoglauca and $S$. nigrum) with high antiparasitic activity were further fractionated with different polarity solvents and then investigated for their antiparasitic activity against Gyrodactylus kobayashii and acute toxicity against its host, goldfish (Carassius auratus). Also, to explore the potential mechanism of antiparasitic activity of dioscin, an active compound isolated from $D$. collettii var. hypoglauca, the in vitro and in vivo assays were conducted and the morphological alterations of G. kobayashii after exposure to dioscin were examined by scanning electron microscopy. Moreover, the histopathological alterations in goldfish after exposure to dioscin were investigated to explore the influence of dioscin on the experimental fish. These results might help understand the underlying antiparasitic mechanism of dioscin and facilitate its further exploitation and practical application in aquaculture.

\section{MATERIALS AND METHODS}

\section{Fish-Parasite Model}

Healthy goldfish (mean body weight of $4.37 \pm 0.58 \mathrm{~g}$ ) were obtained from a local fish farm (Hanjin Ornamental Fish Farm, Wuhan, China) and then subjected to continuous baths with suitable concentrations of formalin solutions for $12 \mathrm{~h}$ at 48 $\mathrm{h}$ intervals to remove all ectoparasites after acclimation for 7 days. Ten goldfish were randomly selected for parasitological examination to ensure these fish were free of ectoparasites after a 30-day recovery. And then, G. kobayashii-infected goldfish maintained in the laboratory were mix-cultured with these ectoparasite-free goldfish for about 10 days at a ratio of 1:4 to obtain more infected goldfish. The goldfish-G. kobayashii model has been established and maintained in the laboratory referring to the methods reported in previous studies $(24,25)$.

\section{Preparation of Plant Materials and Chemicals}

Thirty-six dried plant materials (Table 1) were purchased from a local Chinese pharmacy and then dried in an oven at $60^{\circ} \mathrm{C}$ for $48 \mathrm{~h}$. These dry plant materials were then ground into powder with an electric grinder and freeze-dried at $-45^{\circ} \mathrm{C}$ to completely remove water. The dry powder $(30 \mathrm{~g})$ of each plant material was extracted with $300 \mathrm{~mL}$ of anhydrous ethanol 3 times at $25^{\circ} \mathrm{C}$; each extraction lasted for $48 \mathrm{~h}$ in a static state. Then the extracts 
TABLE 1 | Summary of tested plants used in the trial.

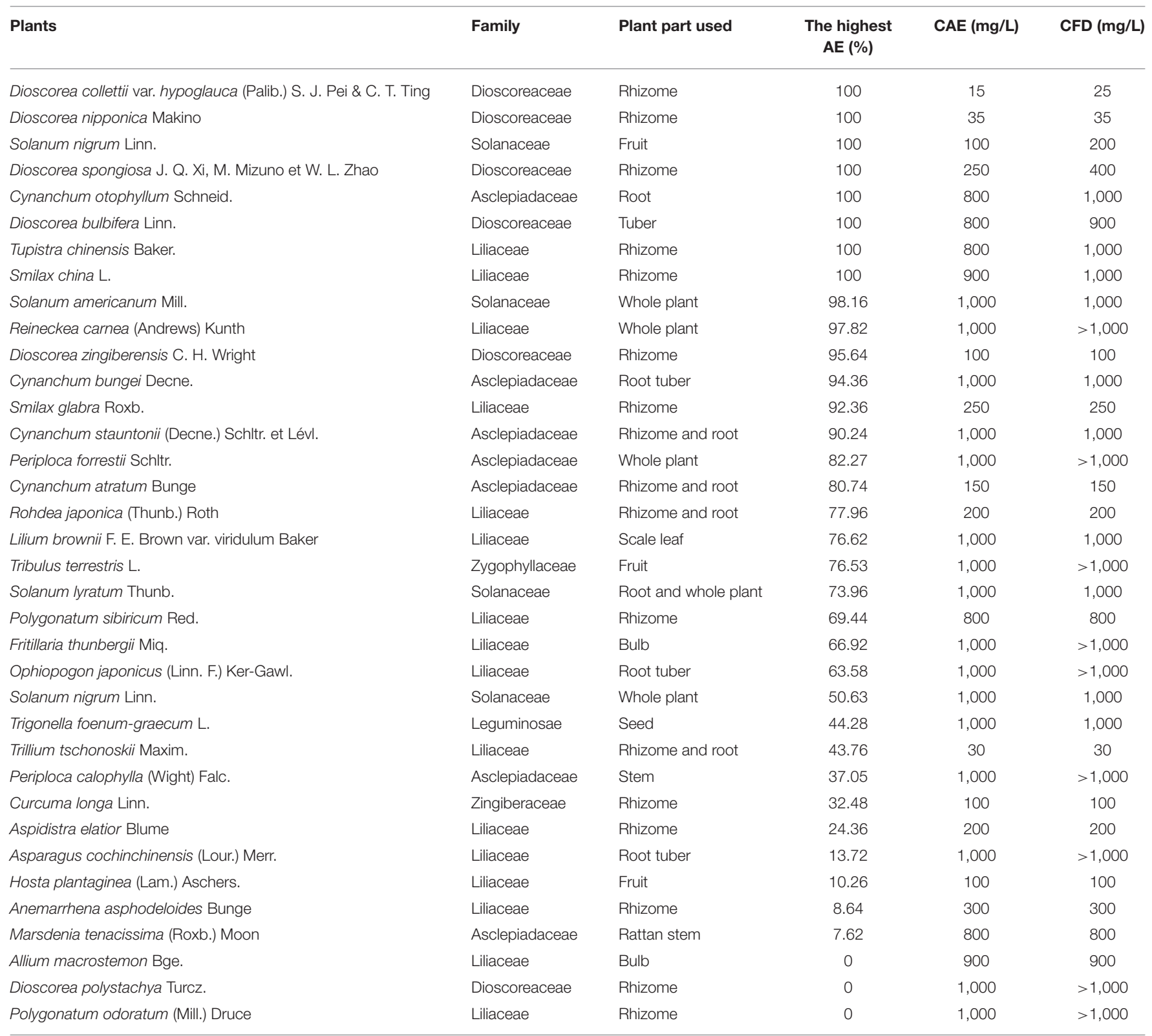

$A E$, Antiparasitic efficacy against Gyrodactylus kobayashii in goldfish (Carassius auratus) of ethanol extracts; CAE, the concentration with the best AE; CFD, the concentration causing fish mortality.

were percolated through filter paper and concentrated under reduced pressure in a vacuum rotary evaporator (YRE2000E) at $50^{\circ} \mathrm{C}$ to obtain solidified crude extracts, which were then dissolved in dimethyl sulfoxide (DMSO) to get $0.5 \mathrm{~g} / \mathrm{mL}$ (sample/solvent) stocking solutions. Dioscin was purchased from Shanghai Yuanye Biotech Co., Ltd. (Shanghai, China) and then dissolved in DMSO to get $2 \mathrm{mg} / \mathrm{mL}$ stocking solutions.

\section{In vivo Screening of $\mathbf{3 6}$ Plant Extracts for Antiparasitic Efficacy}

Antiparasitic efficacy of these ethanol extracts against $G$. kobayashii was evaluated in 720 1-L tanks containing one infected goldfish and $0.5 \mathrm{~L}$ of dechlorinated water at $23.0 \pm 0.6^{\circ} \mathrm{C}$. A negative control group without drugs and a positive control group containing $0.2 \%$ DMSO were set up under the same conditions as the test groups. Formaldehyde, a widely used agent to treat gyrodactylosis, was also evaluated as a positive control agent with concentrations of 15, 20,25, 30, and 35 $\mathrm{mg} / \mathrm{L}$. For ethanol extracts of 36 tested herbal medicines, the concentrations used in this trial ranged $15-100 \mathrm{mg} / \mathrm{L}$ for ethanol extracts of $D$. collettii var. hypoglauca, Dioscorea nipponica, Dioscorea zingiberensis, Trillium tschonoskii, Curcuma longa and Hosta plantaginea, and ranged from 100 to $300 \mathrm{mg} / \mathrm{L}$ for ethanol extracts of S. nigrum, Dioscorea spongiosa, Smilax 
glabra, Cynanchum atratum, Rohdea japonica, Aspidistra elatior and Anemarrhena asphodeloides. The concentrations of the remaining ethanol extracts ranged from 600 to $1,000 \mathrm{mg} / \mathrm{L}$. All experiments were performed in ten replicates. Normally swimming goldfish with medium infection intensity (40200 parasites/fish) were chosen for the in vivo assay. The experimental fish was anesthetized with $0.02 \%$ MS222 (tricaine methanesulfonate) and the number of G. kobayashii on the caudal fin was counted under a stereomicroscope at 0 and $48 \mathrm{~h}$ post-treatment. Antiparasitic efficacy was calculated according to the methods described in a previous study and the formula was as follows: $\mathrm{E}=\left(\mathrm{L}_{-} \mathrm{L}_{\mathrm{t}}\right) / \mathrm{L} \times 100 \%$ for $\mathrm{L}>\mathrm{L}_{\mathrm{t}}, \mathrm{E}=0$ for $\mathrm{L} \leq \mathrm{L}_{\mathrm{t}}$. In this formula, $\mathrm{E}$ is antiparasitic efficacy, $\mathrm{L}$ is the infection intensity of $G$. kobayashii before treatment, and $\mathrm{L}_{\mathrm{t}}$ is the infection intensity after 48-h treatment (25-27).

Based on effectiveness, safety and dosage, D. collettii var. hypoglauca and S. nigrum were selected for further extraction tests with different polarity solvents: water, methanol, ethyl acetate and petroleum ether. These extracts were obtained and then evaluated for their antiparasitic efficacy according to the afore-mentioned methods. For different polarity solvents extracts of $D$. collettii var. hypoglauca and $S$. nigrum, the concentrations used in the in vivo assay were presented in Figures 1, 2 and ranged from 2 to $200 \mathrm{mg} / \mathrm{L}$ for methanol and ethyl acetate

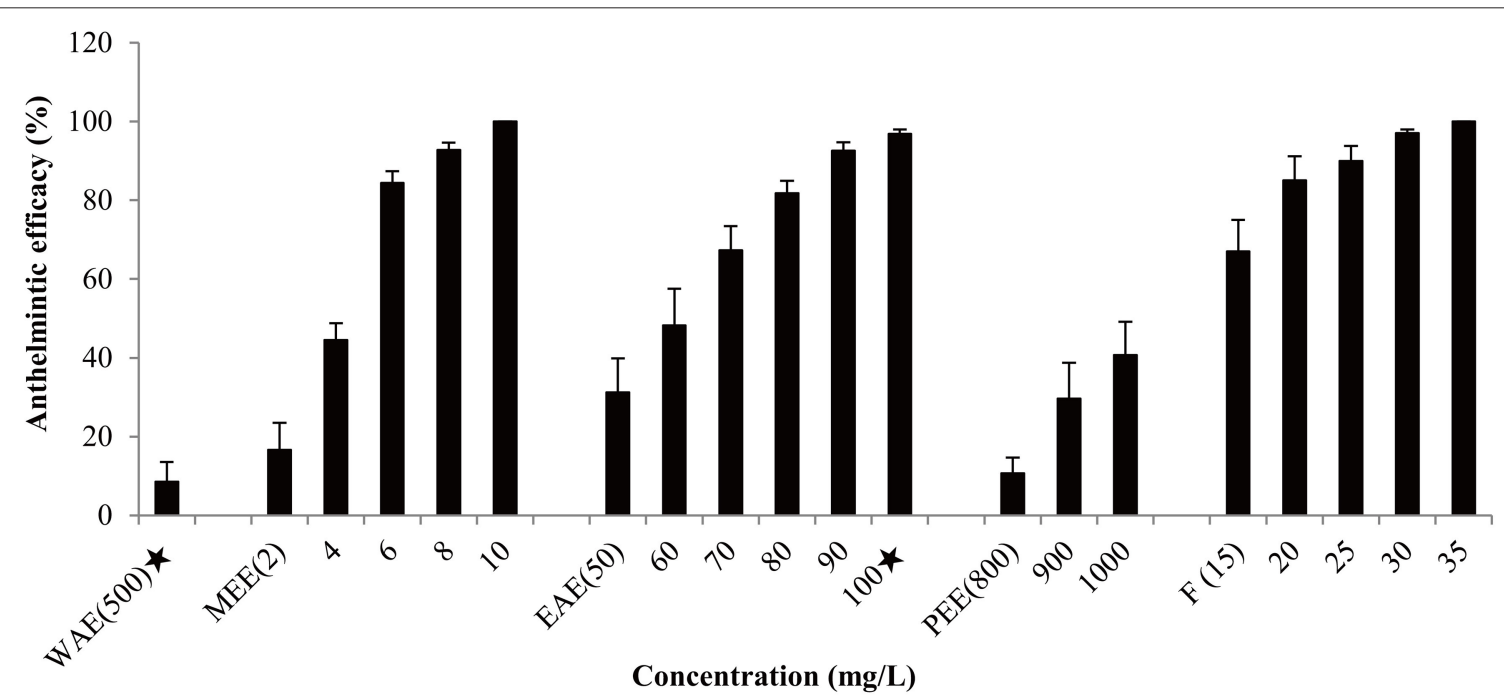

FIGURE 1 | Antiparasitic efficacy of different extracts of Dioscorea collettii var. hypoglauca and formaldehyde against Gyrodactylus kobayashii after a 48-h treatment. WAE, water extract; MEE, methanol extract; EAE, ethyl acetate extract; PEE, petroleum ether extract; F, formaldehyde. A star indicates that fish death occurred.

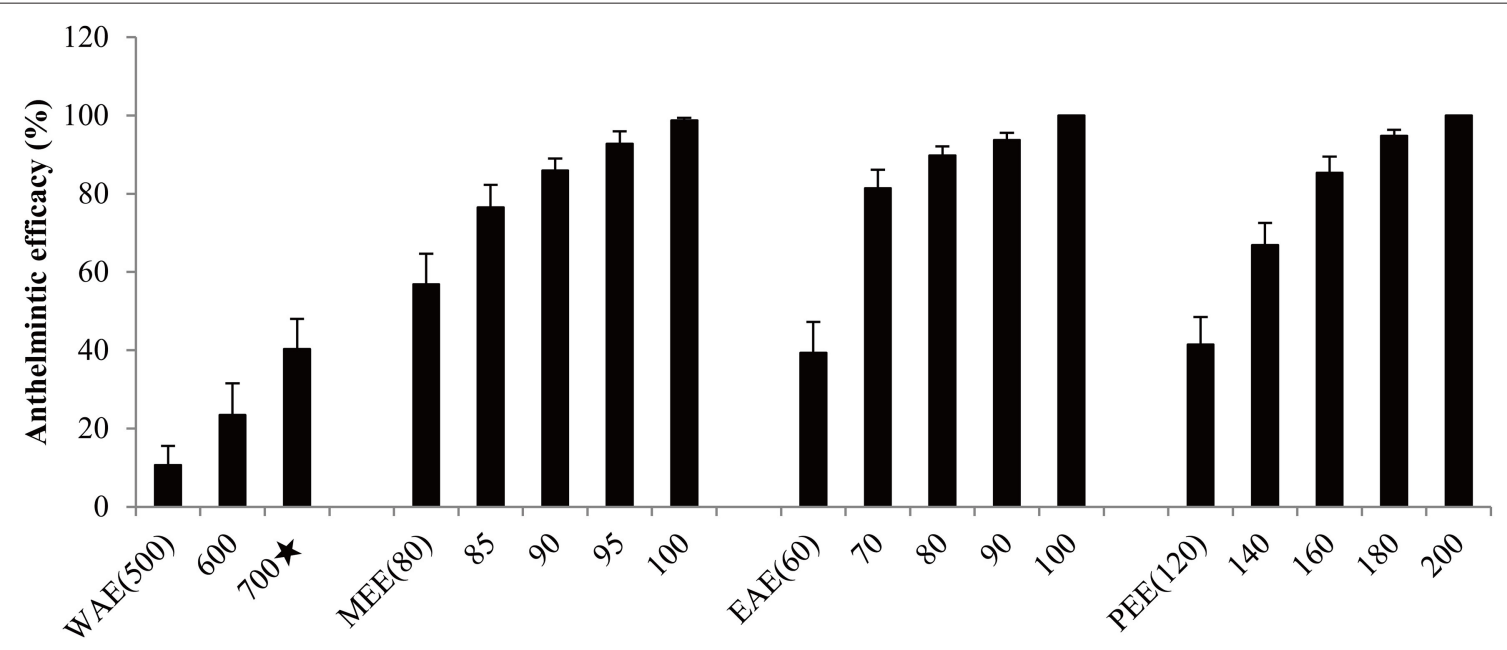

Concentration $(\mathrm{mg} / \mathrm{L}$

FIGURE 2 | Antiparasitic efficacy of different extracts of Solanum nigrum against Gyrodactylus kobayashii after a 48-h treatment. WAE, water extract; MEE, methano extract; EAE, ethyl acetate extract; PEE, petroleum ether extract. A star indicates that fish death occurred. 
extracts of these two plants and petroleum ether extract of $S$. nigrum. The concentrations of the remaining extracts ranged from 500 to $1,000 \mathrm{mg} / \mathrm{L}$.

\section{Acute Toxicity Tests of Selected Extracts Against Goldfish}

To evaluate the safety margin of different extracts of $D$. collettii var. hypoglauca and S. nigrum, acute toxicity tests against goldfish were conducted using an aqueous static bioassay method. A batch of healthy goldfish were randomly placed into 117 10-L aquariums (10 fish/aquarium) with $6 \mathrm{~L}$ of dechlorinated water and exposed to tested extracts for $48 \mathrm{~h}$ at $23.0 \pm 0.6^{\circ} \mathrm{C}$. The concentrations used in the acute toxicity tests ranged from 10 to $300 \mathrm{mg} / \mathrm{L}$ for methanol and ethyl acetate extracts of $D$. collettii var. hypoglauca and methanol extracts of $S$. nigrum. The concentrations of the remaining five extracts ranged from 400 to $1,000 \mathrm{mg} / \mathrm{L}$ (Table 3). A negative control group without drugs and a positive control group containing $0.2 \%$ DMSO were set up under the same conditions. Acute toxicity of formaldehyde $(30,40,50,60$, and $70 \mathrm{mg} / \mathrm{L})$ to goldfish was also evaluated. Three replicate aquariums were used for all treatment and control groups. Dead fish were recorded and immediately removed during the 48-h continuous exposure.

\section{In vitro Antiparasitic Efficacy of Dioscin Against G. kobayashii}

Parasites were gently dislodged from the caudal fin of $G$. kobayashii-infected goldfish after anesthesia with MS-222 using fine insect pins under a stereomicroscope $(28,29)$. The individual parasite was randomly selected and transferred to a 24 -well microtiter plate in $50 \mu \mathrm{L}$ of dechlorinated water using a micropipette (a single worm per well). Each well was then added with $350 \mu \mathrm{L}$ of dechlorinated water and cultured at $23.0 \pm$ $0.6^{\circ} \mathrm{C}$. After an hour of acclimatization, all wells were examined and the parasites that died or showed any abnormal behavior were excluded from the experiment. Then $100 \mu \mathrm{L}$ of different concentrations of stock solutions were added to achieve the required concentrations $(0.3,0.4,0.5$, and $0.6 \mathrm{mg} / \mathrm{L})$ and the time was defined as zero. A control group (a single parasite and $500 \mu \mathrm{L}$ of dechlorinated water containing $0.06 \%$ DMSO in each well) was set up under the same conditions. Four parallel plates were used for all experimental groups. Subsequently, these parasites were observed every 1 or $2 \mathrm{~h}$ for their status until death occurred. The parasites that showed no response after a gentle stimulation by an insect pin were considered dead.

\section{In vivo Antiparasitic Efficacy of Dioscin Against G. kobayashii}

The in vivo antiparasitic tests of dioscin were conducted as the above-described methods. Fifty infected goldfish were randomly placed into fifty tanks, each containing one infected goldfish and $0.5 \mathrm{~L}$ of dechlorinated water. Then the appropriate volume of stock solution was added into each tank to achieve the required concentrations of $0.6,0.5,0.4,0.3$, and 0 (control group, $0.06 \%$ DMSO) $\mathrm{mg} / \mathrm{L}$ dioscin, respectively. The number of $G$. kobayashii on the caudal fin of the experimental fish was counted under a stereomicroscope at 0 and $24 \mathrm{~h}$ post-treatment and then antiparasitic efficacy was calculated.

Also, to evaluate the speed of parasite clearance of high concentrations of dioscin $(0.4,0.5,0.6,0.7$, and $0.8 \mathrm{mg} / \mathrm{L})$, the in vivo antiparasitic tests were further investigated as the abovedescribed methods with minor modification. At the beginning of the experiment, each experimental fish was placed into a separate plastic box and the parasite load on the caudal fin was counted. Ten replicate plastic boxes were used for all groups (fifty experimental goldfish). Then experimental fish were exposed to various concentrations of dioscin for $4 \mathrm{~h}$ and the infection intensity of G. kobayashii on the caudal fin was examined every $1 \mathrm{~h}$, and antiparasitic efficacy was calculated as aforementioned methods at each time point.

\section{Scanning Electron Microscopy}

To determine whether dioscin caused morphological alterations to G. kobayashii tegument, SEM analysis of gyrodactylids samples was conducted following standard methods (30). In short, G. kobayashii-infected goldfish were exposed to $0.06 \%$ DMSO (control group) and $0.29 \mathrm{mg} / \mathrm{L}$ dioscin $\left(24 \mathrm{~h}-\mathrm{EC}_{50}\right)$ for $12 \mathrm{~h}$. Caudal fins with gyrodactylids were clipped and fixed in $2.5 \%$ glutaraldehyde solution for $24 \mathrm{~h}$ at $4^{\circ} \mathrm{C}$, and then dehydrated by an alcohol gradient, dried with carbon dioxide and sputtercoated with gold particles. Finally, these processed samples were visualized using a scanning electron microscope (Hitachi SU8010, Tokyo, Japan).

\section{Histopathological Analysis After Exposures to Dioscin}

To explore the influence of dioscin on the experimental fish, the histopathological alterations in goldfish after exposure to dioscin were investigated. Healthy goldfish were exposed to $0.06 \%$ DMSO (control group) and $0.6 \mathrm{mg} / \mathrm{L}$ dioscin $\left(24 \mathrm{~h}-\mathrm{EC}_{100}\right)$ for $96 \mathrm{~h}$, and the gill tissues from 10 fish (five fish per treatment) were sampled for histopathological analysis. To explore the influence of a high concentration of dioscin on the experimental fish, five healthy goldfish were subjected to therapeutic baths with $0.7 \mathrm{mg} / \mathrm{L}$ dioscin for $1 \mathrm{~h}$ and the gill tissues were also collected. All gill tissues were fixed in a $4 \%$ paraformaldehyde solution for $48 \mathrm{~h}$ and then dehydrated by an alcohol gradient, rinsed in xylene and embedded in paraffin wax. Finally, $5 \mu \mathrm{m}$ sections were cut with a microtome and stained with hematoxylin and eosin, then the histological changes were evaluated using a Primo Star microscope (Carl Zeiss Microscopy GmbH, Jena, Germany).

\section{Statistical Analyses}

The 50 and $90 \%$ effective concentrations for removing $G$. kobayashii $\left(\mathrm{EC}_{50}\right.$ and $\left.\mathrm{EC}_{90}\right)$, and $50 \%$ and $90 \%$ lethal concentrations against goldfish ( $\mathrm{LC}_{50}$ and $\mathrm{LC}_{90}$ ) with $95 \%$ confidence levels (CI) were calculated using the Probit method (31). The therapeutic index (TI) is defined as the ratio of $\mathrm{LC}_{50}$ to $\mathrm{EC}_{50}$ and high $\mathrm{TI}$ indicates a favorable safety (32). The survival rate of G. kobayashii exposed to different concentrations of dioscin was analyzed by Kaplan-Meier log-rank test (33). Statistical analysis was performed using SPSS 20.0 software. 


\section{RESULTS}

\section{In vivo Screening of $\mathbf{3 6}$ Plant Extracts for Antiparasitic Efficacy}

As Shown in Table 1, among the 36 herbal medicines, ethanol extracts of $D$. collettii var. hypoglauca and S. nigrum showed $100 \%$ antiparasitic efficacy at 15 and $100 \mathrm{mg} / \mathrm{L}$ after $48 \mathrm{~h}$ of exposure, respectively. Besides, ethanol extract of $D$. nipponica could completely remove gyrodactylids from goldfish at the concentration of $35 \mathrm{mg} / \mathrm{L}$, but this concentration was lethal to goldfish. Ethanol extracts of five herbal medicines including D. spongiosa, Cynanchum otophyllum, Dioscorea bulbifera, Tupistra chinensis, and Smilax china also exhibited antiparasitic activity against $G$. kobayashii but at relatively high concentrations. The remaining ethanol extracts of herbal medicines showed varying degrees of antiparasitic efficacy ranging from $98.16 \%$ to 0 .

Antiparasitic efficacy of different extracts of $D$. collettii var. hypoglauca and S. nigrum are illustrated in Figures 1, 2, and the results of the in vivo assay are summarized in Table 2. Among all tested extracts, methanol extract of $D$. collettii var. hypoglauca was the most efficient with $100 \%$ antiparasitic efficacy at a relatively low concentration of $10 \mathrm{mg} / \mathrm{L}$. This extract had low $\mathrm{EC}_{50}$ and $\mathrm{EC}_{90}$ values of 4.17 and $7.04 \mathrm{mg} / \mathrm{L}$ after $48 \mathrm{~h}$ of exposure, respectively. Ethyl acetate extract of $D$. collettii var. hypoglauca also exhibited superior antiparasitic activity with an $\mathrm{EC}_{50}$ value of $60.6 \mathrm{mg} / \mathrm{L}$ and an $\mathrm{EC}_{90}$ value of 87.52 $\mathrm{mg} / \mathrm{L}$. Nevertheless, water and petroleum ether extracts of D. collettii var. hypoglauca showed weak antiparasitic activity even at the concentration of 500 or $1,000 \mathrm{mg} / \mathrm{L}$ (Figure 1 and Table 2). In the case of $S$. nigrum, methanol and ethyl acetate extracts showed 98.72 and $100 \%$ antiparasitic efficacy at the concentration of $100 \mathrm{mg} / \mathrm{L}$, respectively (Figure 2 and Table 2). Water and petroleum ether extracts exhibited weak antiparasitic activity with relatively high $\mathrm{EC}_{50}$ values (more than $100 \mathrm{mg} / \mathrm{L}$ ). In the two control groups, a significant rise in the gyrodactylids load in goldfish was observed, indicating that $0.2 \%$ DMSO and dechlorinated water showed no antiparasitic activity against G. kobayashii. As a positive control agent, formaldehyde showed $100 \%$ antiparasitic efficacy at $35 \mathrm{mg} / \mathrm{L}$ with $\mathrm{EC}_{50}$ and
$\mathrm{EC}_{90}$ values of 10.5 and $23.4 \mathrm{mg} / \mathrm{L}$, respectively (Figure 1 and Table 2).

\section{Acute Toxicity Tests of Selected Extracts Against Goldfish}

The results of acute toxicity tests of different extracts are presented in Table 3. Among all tested extracts, only two had higher TI values than that of a widely used parasiticideformaldehyde (TI value of 4.58), namely methanol extract of $D$. collettii var. hypoglauca (TI value of 5.26) and ethyl acetate extract of S. nigrum (TI value of 10.99). Petroleum ether extracts of these two herbal medicines exhibited low acute toxicity to goldfish; only one or two dead fish were observed at the concentration of $1,000 \mathrm{mg} / \mathrm{L}$. The remaining extracts had lower TI values than formaldehyde. In the control groups with no drug and DMSO, no deaths were observed, suggesting that the impact of DMSO on goldfish should be negligible.

\section{In vitro and in vivo Antiparasitic Efficacy of Dioscin Against G. kobayashii}

The cumulative survival of $G$. kobayashii in vitro decreased with increasing concentrations of dioscin (Figure 3), and a significant difference in the survival curves at different concentrations of dioscin was observed $(P<0.01)$. Mean survival time of $G$. kobayashii in vitro decreased in a dose-dependent manner and was reduced from $18.02 \mathrm{~h}$ in the control group to $4.99 \mathrm{~h}$ at the concentration of $0.6 \mathrm{mg} / \mathrm{L}$ dioscin (Table 4). At the high concentrations of dioscin $(0.5$ and $0.6 \mathrm{mg} / \mathrm{L})$, the rapid and irregular twisting movements of the worms were observed just after exposure to dioscin, and the skin of the worms shrank and turned black within $1 \mathrm{~h}$.

In vivo trial indicated that dioscin showed significant antiparasitic activity, with a $24 \mathrm{~h}-\mathrm{EC}_{50}$ value of $0.29 \mathrm{mg} / \mathrm{L}$, and it exhibited $100 \%$ antiparasitic efficacy against G. kobayashii at $0.6 \mathrm{mg} / \mathrm{L}$ (Figure 4A). The therapeutic baths with $0.5 \mathrm{mg} / \mathrm{L}$ of dioscin for $4 \mathrm{~h}$ could decrease $97.82 \%$ parasite loads in goldfish. Furthermore, all gyrodactylids could be completely eliminated from goldfish within $2 \mathrm{~h}$ at a concentration of $0.6 \mathrm{mg} / \mathrm{L}$ dioscin, and within $1 \mathrm{~h}$ at a concentration of $0.7 \mathrm{mg} / \mathrm{L}$ dioscin (Figure 4B).

TABLE 2 | Antiparasitic efficacy $\left(\mathrm{EC}_{50}\right.$ and $\left.\mathrm{EC}_{90}\right)$ of different extracts from Dioscorea collettii var. hypoglauca and Solanum nigrum against Gyrodactylus kobayashii after $48 \mathrm{~h}$ of exposure.

\begin{tabular}{|c|c|c|c|c|c|}
\hline Plants or agents & Extraction solvent & $\mathrm{EC}_{50}(\mathrm{mg} / \mathrm{L})$ & $95 \% \mathrm{Cl}$ & $\mathrm{EC}_{90}(\mathrm{mg} / \mathrm{L})$ & $95 \% \mathrm{Cl}$ \\
\hline \multirow[t]{4}{*}{ D. collettii var. hypoglauca } & Water & $>500$ & - & - & - \\
\hline & Methanol & 4.17 & $3.82-4.5$ & 7.04 & $6.6-7.61$ \\
\hline & Ethyl acetate & 60.6 & $57.44-63.27$ & 87.52 & 83.99-92.1 \\
\hline & Petroleum ether & $>1,000$ & - & - & - \\
\hline \multirow[t]{4}{*}{ S. nigrum } & Water & 748.26 & $701.44-847$ & 1005.43 & 889.99-1275.11 \\
\hline & Methanol & 77.9 & $74.49-80.13$ & 91.85 & $90.09-94.3$ \\
\hline & Ethyl acetate & 61.46 & $39.76-68.68$ & 80.62 & $73.41-102.14$ \\
\hline & Petroleum ether & 126.99 & 120.66-131.94 & 166.14 & $160.67-173.43$ \\
\hline Formaldehyde & - & 10.5 & $6.1-13.1$ & 23.4 & $21.8-25.6$ \\
\hline
\end{tabular}

$E C_{50}$, effective concentration with 50\% Antiparasitic efficacy; CC $90_{9}$, effective concentration with 90\% Antiparasitic efficacy; $95 \%$ Cl, 95\% confidence interval; -, not calculated. 
TABLE 3 | Acute toxicity of different extracts from Dioscorea collettii var. hypoglauca and Solanum nigrum against goldfish after 48 h of exposure.

\begin{tabular}{|c|c|c|c|c|c|c|}
\hline Plants or agents & $\begin{array}{l}\text { Extraction } \\
\text { solvent }\end{array}$ & $\mathrm{LC}_{50}(\mathrm{mg} / \mathrm{L})$ & $95 \% \mathrm{Cl}$ & $\mathrm{LC}_{90}(\mathrm{mg} / \mathrm{L})$ & $95 \% \mathrm{Cl}$ & $\begin{array}{c}\text { TI } \\
\left(\mathrm{LC}_{50} / \mathrm{EC}_{50}\right)\end{array}$ \\
\hline \multirow[t]{4}{*}{ D. collettii var. hypoglauca } & Water & 778.48 & 723.24-838.59 & 1130.72 & $1026.27-1329.12$ & - \\
\hline & Methanol & 21.93 & $20.15-23.84$ & 31.53 & $28.74-36.19$ & 5.26 \\
\hline & Ethyl acetate & 194.33 & 179.37-209.25 & 267.01 & 247.05-297.78 & 3.21 \\
\hline & $\begin{array}{l}\text { Petroleum } \\
\text { ether }\end{array}$ & $>1,000$ & - & - & - & - \\
\hline \multirow[t]{4}{*}{ S. nigrum } & Water & 905.98 & 869.82-951.74 & 1088.35 & 1023.65-215.53 & 1.21 \\
\hline & Methanol & 160.79 & 152.66-169.02 & 205.26 & 192.73-226.86 & 2.06 \\
\hline & Ethyl acetate & 675.37 & 640.05-716.95 & 864.98 & 805.2-967.84 & 10.99 \\
\hline & $\begin{array}{l}\text { Petroleum } \\
\text { ether }\end{array}$ & $>1,000$ & - & - & - & - \\
\hline Formaldehyde & - & 48.1 & $44.5-51.6$ & 61.5 & $57.1-68.9$ & 4.58 \\
\hline
\end{tabular}

LC $50,50 \%$ lethal concentration; LC 90 , 90\% lethal concentration; $95 \%$ Cl, 95\% confidence interval; TI, therapeutic index; -, not calculated.

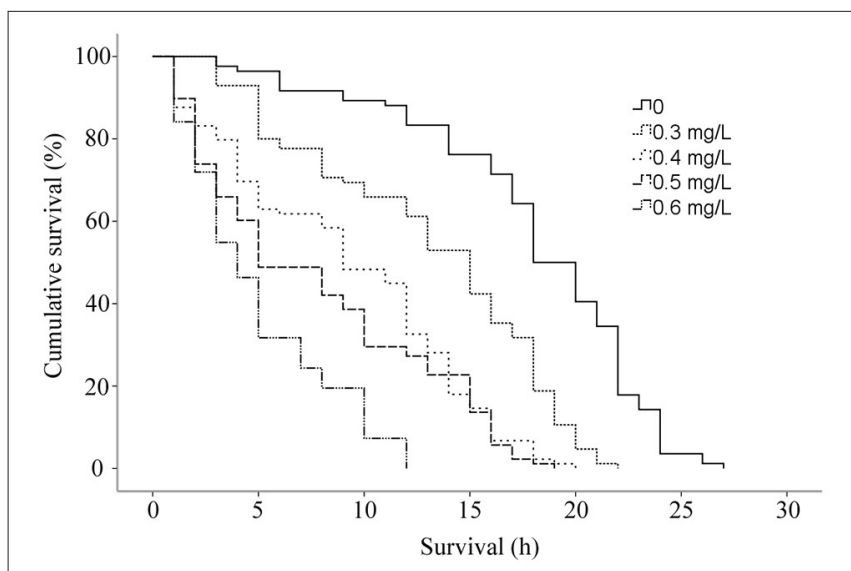

FIGURE 3 | Cumulative survival (\%) in vitro of Gyrodactylus kobayashii at different concentrations of dioscin.

\section{Scanning Electron Microscopy}

The morphological alterations of G. kobayashii tegument after exposure to dioscin observed by SEM are shown in Figure 5. G. kobayashii exposed to $0.06 \%$ DMSO (control group) displayed a defined body shape and dense microvilli on the tegument surface (Figures 5A,C,E). In contrast, parasites treated with $0.29 \mathrm{mg} / \mathrm{L}$ dioscin displayed substantial tegumental damage and most of the microvilli on the tegument surface dropped (Figures 5B,D,F).

\section{Histopathological Analysis After Exposures to Dioscin}

The structural details of the gill tissues of experimental goldfish are shown in Figure 6. In the control group, a normal morphological structure with each gill filament supporting a series of secondary gill lamellae was observed (Figure 6A). The gills of goldfish in the treatment groups showed an intact structural organization but with histopathological changes, including hyperplasia, detachment of lamellar epithelium, edema and curling and abnormal elongation of the secondary lamellae (Figures 6B,C).

\section{DISCUSSIONS}

In the current study, 36 kinds of herbal medicines containing saponins were obtained and investigated for the in vivo antiparasitic activity against $G$. kobayashii in goldfish. Based on the screening results, there was a considerable difference in the antiparasitic activity of these herbal medicines, despite all of them containing saponins. For example, ethanol extracts of D. collettii var. hypoglauca, D. nipponica, and S. nigrum showed $100 \%$ antiparasitic efficacy at relatively low concentrations, while ethanol extracts of Marsdenia tenacissima, Allium macrostemon, Dioscorea polystachya, and Polygonatum odoratum exhibited weak or no antiparasitic activity even at the concentration of $1,000 \mathrm{mg} / \mathrm{L}$. Even for more closely related herbal medicines, such as $D$. collettii var. hypoglauca and D. spongiosa, slight changes in the saponin content might lead to a great difference in antiparasitic activity (34). The difference in the antiparasitic activity might thus be due to the varying contents of saponins in different herbal medicines. Besides, ethanol extracts of $D$. spongiosa, C. otophyllum, D. bulbifera, T. chinensis, and S. china also exhibited $100 \%$ antiparasitic activity against G. kobayashii but at relatively high concentrations. These results indicated that some active ingredients with antiparasitic activity exist in these extracts and need to be further isolated.

Based on effectiveness, safety and dosage, D. collettii var. hypoglauca and S. nigrum were selected for further extraction with different polarity solvents and then evaluated for their antiparasitic efficacy. Among all tested extracts, methanol extract of $D$. collettii var. hypoglauca was the most efficient, with $\mathrm{EC}_{50}$ and $\mathrm{EC}_{90}$ values of 4.17 and $7.04 \mathrm{mg} / \mathrm{L}$, respectively. This extract exhibited $100 \%$ antiparasitic efficacy against G. kobayashii at a concentration of $10 \mathrm{mg} / \mathrm{L}$, which is lower than that of methanol extract of $P$. polyphylla, an effective alternative agent to control gyrodactylids infections identified in a previous study (14). To our knowledge, the economic cost is an important determinant 
TABLE 4 | In vitro effects of dioscin on Gyrodactylus kobayashii.

\begin{tabular}{|c|c|c|c|c|c|}
\hline Agents & $\begin{array}{l}\text { Concentrations } \\
\text { (mg/L) }\end{array}$ & Sample sizes & $\begin{array}{c}\text { Mean } \\
\text { survival } \\
\text { time (h) }\end{array}$ & $\begin{array}{l}\text { Standard } \\
\text { error }\end{array}$ & $\begin{array}{c}\text { Range of } \\
\text { survival time } \\
\text { (h) }\end{array}$ \\
\hline \multirow[t]{5}{*}{ Dioscin } & 0 & 84 & 18.02 & 0.61 & $3-27$ \\
\hline & 0.3 & 85 & 13.05 & 0.62 & $3-22$ \\
\hline & 0.4 & 89 & 9.17 & 0.51 & $1-20$ \\
\hline & 0.5 & 88 & 7.72 & 0.6 & $1-19$ \\
\hline & 0.6 & 82 & 4.99 & 0.38 & $1-12$ \\
\hline
\end{tabular}

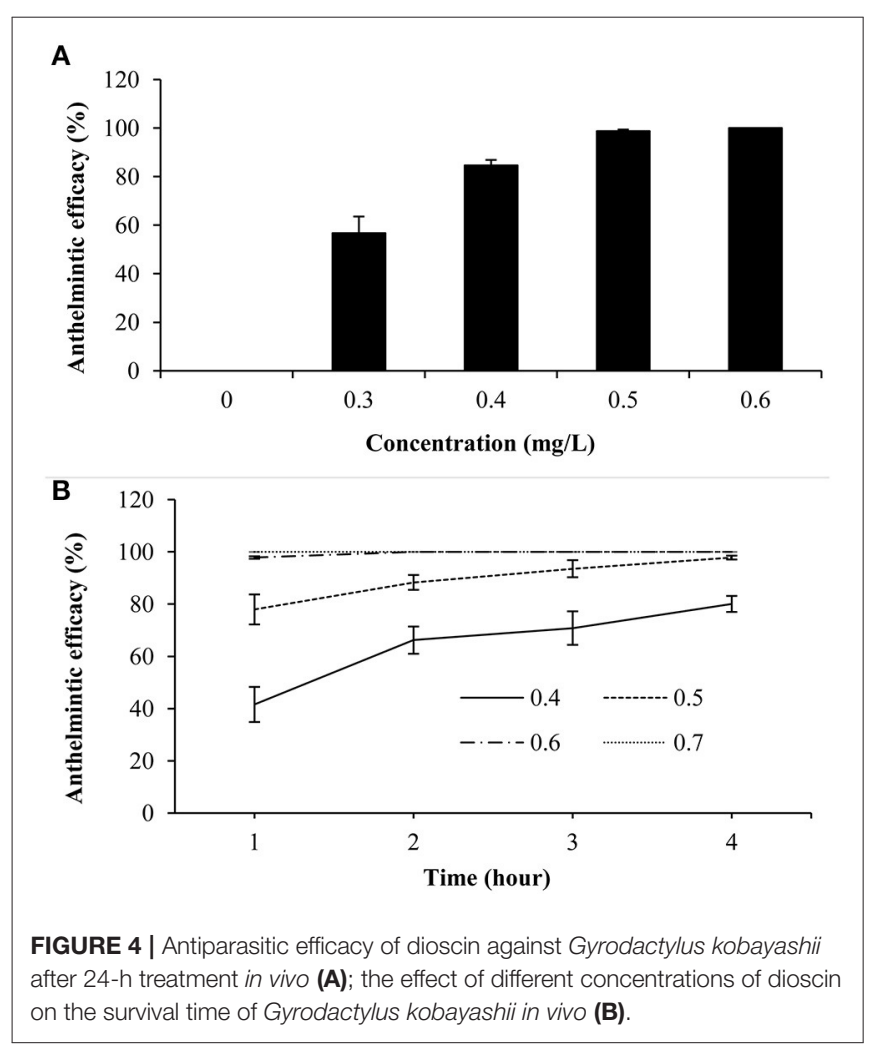

of the development of natural antiparasitic agents. The market price of $D$. collettii var. hypoglauca is far lower than that of $P$. polyphylla, which would increase the feasibility of the practical application of this herbal medicine. Besides, methanol extract of D. collettii var. hypoglauca had a TI value of 5.26, which is higher than that of formaldehyde ( $\mathrm{TI}=4.58)$, a widely used parasiticide in aquaculture. These results indicated that methanol extract of $D$. collettii var. hypoglauca was superior to formaldehyde in terms of antiparasitic efficacy and safety and thus might have the potential to be a novel antiparasitic agent to treat gyrodactylosis.

Besides, the in vivo trial indicated that the worms could be completely removed within $2 \mathrm{~h}$ at a concentration of $0.6 \mathrm{mg} / \mathrm{L}$. Surprisingly, mean survival time of $G$. kobayashii in vitro was $4.99 \mathrm{~h}$, and some individuals even reached $12 \mathrm{~h}$ after exposure to $0.6 \mathrm{mg} / \mathrm{L}$ dioscin. These results indicated that time to death of $G$. kobayashii was longer than time to detachment from host

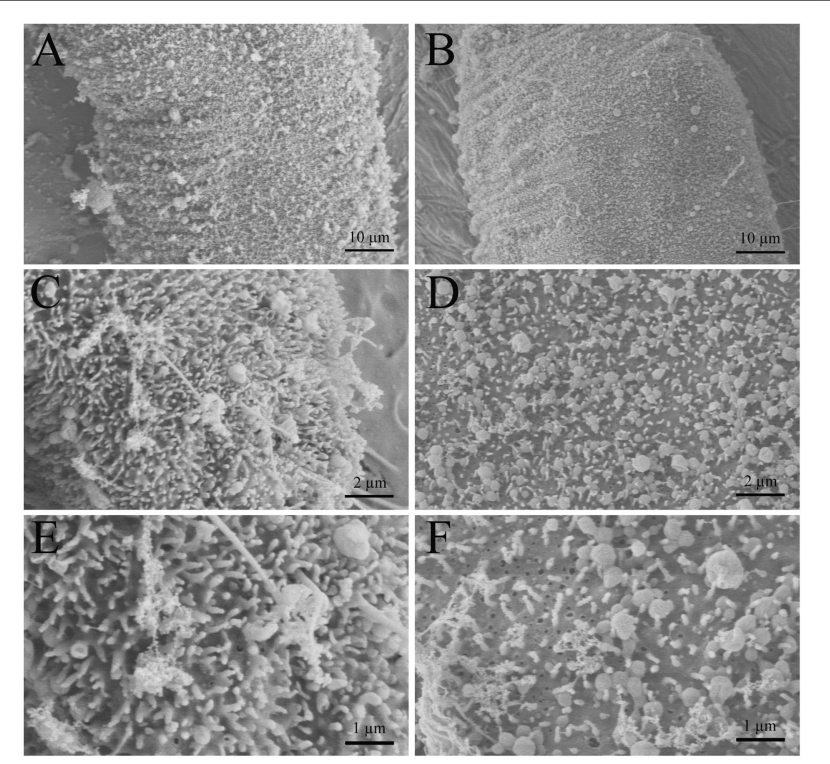

FIGURE 5 | Scanning electron microscopy (SEM) of Gyrodactylus kobayashii exposed to dioscin. Control group: worms exposed to $0.06 \%$ DMSO for $12 \mathrm{~h}$ (A,C,E), treatment group: worms exposed to $0.3 \mathrm{mg} / \mathrm{L}$ dioscin for $12 \mathrm{~h}$ $(B, D, F)$.

after exposure to dioscin, and $0.6 \mathrm{mg} / \mathrm{L}$ of dioscin did not completely kill all worms within $2 \mathrm{~h}$, but just temporarily remove the worms from goldfish. A similar phenomenon was observed for praziquantel and mebendazole, which caused detachment of the parasites before full death (35). Also, the in vitro observation showed that exposure to a high concentration of dioscin caused rapid and irregular twisting movements of the parasites, which might be one of the reasons why the parasites rapidly shed from goldfish. Similarly, the worms treated with garlic extract also appeared to contract and twitch violently (36). These results indicated they may have similar modes of action on gyrodactylids, although their antiparasitic mechanisms are unclear. It was worth noting that detached gyrodactylids can survive in vitro for several hours and reinfect when they come into contact with a new host (37). These results would suggest that dioscin should be thus mixed with other antiparasitic drugs in practical applications to avoid the reinfection of the hosts by the detached parasites. Besides, the tegument integrity is 


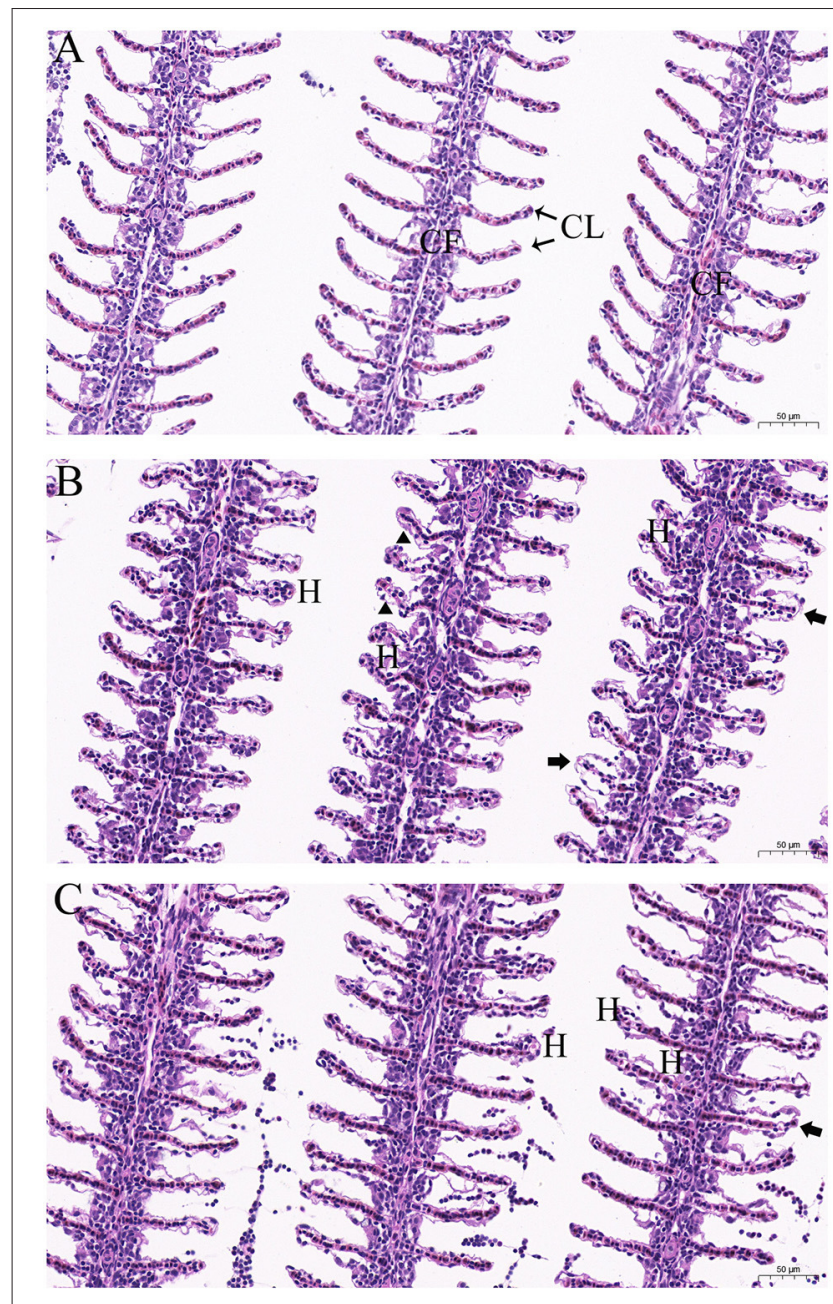

FIGURE 6 | Histopathological characteristics in the gills of goldfish (Carassius auratus) after exposure to different concentrations of dioscin. (A) goldfish gills exposed to $0.06 \%$ DMSO for $96 \mathrm{~h}$ (control group), gill filament (GF) and gill lamellae (GL); (B) goldfish gills exposed to $0.6 \mathrm{mg} / \mathrm{L}$ dioscin for $96 \mathrm{~h}$,

hyperplasia $(H)$, curling and abnormal elongation of the secondary lamellae (triangles) and detachment of lamellar epithelium (arrows); (C) goldfish gills exposed to $0.7 \mathrm{mg} / \mathrm{L}$ dioscin for $1 \mathrm{~h}$, hyperplasia $(\mathrm{H})$ and detachment of lamellar epithelium (arrows). alteration in the gills of goldfish after exposure to $0.6 \mathrm{mg} / \mathrm{L}$ dioscin for $96 \mathrm{~h}$ or $0.7 \mathrm{mg} / \mathrm{L}$ dioscin for $1 \mathrm{~h}$. Also, the in vivo trial indicated gyrodactylids could be completely removed from goldfish within $2 \mathrm{~h}$ at a concentration of $0.6 \mathrm{mg} / \mathrm{L}$ dioscin, and within $1 \mathrm{~h}$ at a concentration of $0.7 \mathrm{mg} / \mathrm{L}$ dioscin. Generally, the adverse effects of chemotherapeutic agents on fish are dose and time-dependent, short bath time is thus beneficial to host. Considering both effectiveness and safety, the therapeutic baths with a high concentration of dioscin for a short time (the baths with $0.7 \mathrm{mg} / \mathrm{L}$ for $1 \mathrm{~h}$ ) might thus be a more optimal choice for the treatment of gyrodactylosis in aquaculture.

In the screening experiment, ethanol extract of the fruit of S. nigrum displayed $100 \%$ antiparasitic efficacy at $100 \mathrm{mg} / \mathrm{L}$, whereas ethanol extract of the whole plant of $S$. nigrum showed weak antiparasitic activity of $50.63 \%$ even at the concentration of $1,000 \mathrm{mg} / \mathrm{L}$, which is lethal to goldfish. Glycoalkaloids, such as solamargine and solasonine, are believed to be the main active components of S. nigrum. The content of solasodine, the aglycone of the above-mentioned glycoalkaloids, is much higher in the fruit of $S$. nigrum than in the rest of the plant, which might be the underlying reason for the high antiparasitic activity of $S$. nigrum fruit extract $(21,38,39)$. Also, ethyl acetate extract of $S$. nigrum fruit exhibited $100 \%$ antiparasitic activity at $100 \mathrm{mg} / \mathrm{L}$ with a TI value of 10.99, which is higher than that of formaldehyde. These results demonstrated that ethyl acetate extract of $S$. nigrum was safer than formaldehyde and exhibited considerable potential as an antiparasitic agent for the management of gyrodactylids infections.

In summary, this study demonstrated the potential of D. collettii var. hypoglauca and S. nigrum in the treatment of gyrodactylids infection in goldfish. Besides, dioscin showed significant antiparasitic activity and the therapeutic baths with a high concentration of dioscin for a short time might prove to be an effective management strategy in the control of gyrodactylosis in aquaculture. Moreover, these results further support the use of herbal medicines as promising sources of natural antiparasitic agents. Nonetheless, field studies are required to assess antiparasitic efficacy of extracts or active compounds under natural conditions.

\section{DATA AVAILABILITY STATEMENT}

critical to the survival of gyrodactylids (2). SEM analysis showed that most of the microvilli on the tegument surface dropped and obvious tegumental damage was observed after exposure to dioscin. This might be one of the potential mechanisms of antiparasitic activity of dioscin against G. kobayashii.

The therapeutic bath has been one of the most frequently used methods to treat gyrodactylosis in aquaculture and baths with high concentrations of agents inevitably cause adverse effects to fish (7). In teleost fishes, gills are the main respiratory organ and surrounded by agents in the therapeutic baths. The histopathological alterations in goldfish gills were thus investigated to explore the influence of dioscin on the experimental fish. Histopathological analysis indicated an intact structural organization with no severe histopathological
The raw data supporting the conclusions of this article will be made available by the authors, without undue reservation.

\section{ETHICS STATEMENT}

All animal experiments were approved and conducted in compliance with the experimental practices and standards developed by the Animal Welfare and Research Ethics Committee of Yangtze River Fisheries Research Institute (YFI2020zhoushun001). The animals used in this study were derived from commercial sources, and the owners' consent was 
not required. All surviving fish continued to be cultured in the laboratory in accordance with standard breeding procedures.

\section{AUTHOR CONTRIBUTIONS}

The design of the experiment was done by SZ and XA. SZ, JD, and YL: methodology. QY, NX, and YY: data collection and analysis. SZ and XA: writing of the manuscript. All authors have read and approved the manuscript.

\section{REFERENCES}

1. Johnsen BO, Jenser AJ. The Gyrodactylus story in Norway. Aquaculture. (1991) 98:289-302. doi: 10.1016/0044-8486(91)90393-L

2. Bakke TA, Cable J, Harris PD. The biology of gyrodactylid monogeneans: the "Russian-doll killers." $A d v$ Parasitol. (2007) 64:161-376. doi: 10.1016/S0065-308X(06) 64003-7

3. Sereno-Uribe AL, Zambrano L, Garcia-Varela M. Reproduction and survival under different water temperatures of Gyrodactylus mexicanus (platyhelminthes: Monogenea), a parasite of Girardinichthys multiradiatus in central Mexico. J Parasitol. (2012) 98:1105-8. doi: 10.1645/GE-3053.1

4. Schelkle B, Faria PJ, Johnson MB, van Oosterhout C, Cable J. Mixed infections and hybridisation in monogenean parasites. PLOS ONE. (2012) 7:e39506. doi: 10.1371/journal.pone.0039506

5. Cable J, Harris PD, Bakke TA. Population growth of Gyrodactylus salaris (Monogenea) on Norwegian and Baltic Atlantic salmon (Salmo salar) stocks. Parasitology. (2000) 121:621-9. doi: 10.1017/S0031182000006971

6. Heggberget TG, Johnsen BO. Infestations by Gyrodactylus sp of Atlantic salmon, Salmo salar L, in Norwegian rivers. J Fish Biol. (1982) 21:15-26. doi: 10.1111/j.1095-8649.1982.tb02819.x

7. Schelkle B, Shinn AP, Peeler E, Cable J. Treatment of gyrodactylid infections in fish. Dis Aqua Organ. (2009) 86:65-75. doi: 10.3354/dao02087

8. Pietrak M, Backman S. Treatment of lumpfish (Cyclopterus lumpus L.) infected with Gyrodactylus cyclopteri (Scyborskaya 1948). J Fish Dis. (2018) 41:721-3. doi: 10.1111/jfd.12781

9. Goven BA, Amend DF. Mebendazole/trichlorfon combination: a new anthelmintic for removing monogenetic trematodes from fish. J Fish Biol. (1982) 20:373-8. doi: 10.1111/j.1095-8649.1982.tb03931.x

10. Levy G, Zilberg D, Paladini G, Fridman S. Efficacy of ginger-based treatments against infection with Gyrodactylus turnbulli in the guppy [Poecilia reticulata (Peters)]. Vet Parasitol. (2015) 209:235-41. doi: 10.1016/j.vetpar.2015.03.002

11. Buchmann K, Roepstorff A, Waller PJ. Experimental selection of mebendazole-resistant gill monogeneans from the European eel, Anguilla anguilla L. J Fish Dis. (1992) 15:393-400. doi: 10.1111/j.1365-2761.1992.tb01238.x

12. Srivastava S, Sinha R, Roy D. Toxicological effects of malachite green. Aqua Toxicol. (2004) 66:319-29. doi: 10.1016/j.aquatox.2003.09.008

13. Van Doan H, Soltani E, Ingelbrecht J, Soltani M. Medicinal herbs and plants: potential treatment of monogenean infections in fish. Rev Fish Sci Aquacult. (2020) 28:260-82. doi: 10.1080/23308249.2020.1712325

14. Zhou S, Dong J, Liu Y, Yang Q, Xu N, Yang Y et al. Anthelmintic efficacy of 35 herbal medicines against a monogenean parasite, Gyrodactylus kobayashii, infecting goldfish (Carassius auratus). Aquaculture. (2020) 521:734992. doi: 10.1016/j.aquaculture.2020.734992

15. Negi JS, Bisht VK, Bhandari AK, Bhatt VP, Singh P, Singh N. Paris polyphylla: chemical and biological prospectives. Anti-Cancer Agents Med Chem. (2014) 14:833-9. doi: 10.2174/1871520614666140611101040

16. Faizal A, Geelen D. Saponins and their role in biological processes in plants. Phytochem Rev. (2013) 12:877-93. doi: 10.1007/s11101-013-9322-4

17. The Pharmacopoeia Commission of People's Republic of China. The Pharmacopoeia of the People's Republic of China, vol. 1. Beijing: China Medical Science and Technology Publishing House (2015).

\section{FUNDING}

The present work was supported by the National Key R\&D Program of China (No. 2019YFD0900104), National Natural Science Foundation of China (No. 31702368) and China Agriculture Research System (CARS-46). The funding bodies had no role in the design of the study or collection, analysis, and interpretation of data or in writing the manuscript.

18. Hu K, Dong AJ, Yao XS, Kobayashi H, Iwasaki S. Antineoplastic agents.2. Four furostanol glycosides from rhizomes of Dioscorea collettii var. hypoglauca. Planta Med. (1997) 63:161-5. doi: 10.1055/s-2006-957636

19. Hu K, Yao XS, Dong AJ, Kobayashi H, Iwasaki S, Jing YK. A new pregnane glycoside from Dioscorea collettii var. hypoglauca. J Nat Products. (1999) 62:299-301. doi: 10.1021/np980101z

20. She GM, Xiao X, Ba YY, Shi RB, Zhang LZ. Chemical constituents of Dioscorea collettii var. hyplauca. Chem Nat Comp. (2013) 49:983-4. doi: 10.1007/s10600-013-0802-y

21. Jain R, Sharma A, Gupta S, Sarethy IP, Gabrani R. Solanum nigrum: Current perspectives on therapeutic properties. Alternat Med Rev. (2011) 16:78-85. Available online at: http://europepmc.org/article/MED/21438649

22. Pestana M, Rodrigues M, Teixeira L, Abrantes ID, Gouveia M, Cordeiro N. In vitro evaluation of nematicidal properties of Solanum sisymbrifolium and S. nigrum extracts on Pratylenchus goodeyi. Nematology. (2014) 16:41-51. doi: 10.1163/15685411-00002743

23. Hammami H, Ayadi A. Molluscicidal and antiparasitic activity of Solanum nigrum villosum against Galba truncatula infected or uninfected with Fasciola hepatica. J Helminthol. (2008) 82:235-9. doi: 10.1017/S0022149X08982584

24. Zhou S, Zou H, Wu SG, Wang GT, Marcogliese DJ, Li WX. Effects of goldfish (Carassius auratus) population size and body condition on the transmission of Gyrodactylus kobayashii (Monogenea). Parasitology. (2017) 144:1221-8. doi: 10.1017/S0031182017000543

25. Zhou S, Li WX, Wang YQ, Zou H, Wu SG, Wang GT. Anthelmintic efficacies of three common disinfectants and extracts of four traditional Chinese medicinal plants against Gyrodactylus kobayashii (Monogenea) in goldfish (Carassius auratus). Aquaculture. (2017) 466:72-7. doi: 10.1016/j.aquaculture.2016.09.048

26. Sommerville C, Endris R, Bell TA, Ogawa K, Buchmann K, Sweeney D. World association for the advancement of veterinary parasitology (WAAVP) guideline for testing the efficacy of ectoparasiticides for fish. Vet Parasitol. (2016) 219:84-99. doi: 10.1016/j.vetpar.2015.11.003

27. Stone J, Sutherland IH, Sommerville CS, Richards RH, Varma KJ. The efficacy of emamectin benzoate as an oral treatment of sea lice, Lepeophtheirus salmonis (KrÒyer), infestations in Atlantic salmon, Salmo salar L. J Fish Stud. (1999) 22:261-70. doi: 10.1046/j.1365-2761.1999.00176.x

28. Schelkle B, Doetjes R, Cable J. The salt myth revealed: treatment of gyrodactylid infections on ornamental guppies, Poecilia reticulata. Aquaculture. (2011) 311:74-9. doi: 10.1016/j.aquaculture.2010.11.036

29. Schelkle B, Snellgrove D, Cable J. In vitro and in vivo efficacy of garlic compounds against Gyrodactylus turnbulli infecting the guppy (Poecilia reticulata). Vet Parasitol. (2013) 198:96-101. doi: 10.1016/j.vetpar.2013.08.027

30. Zhang Y, Tan X, Tu X, Ling F, Wang G. Efficacy and antiparasitic mechanism of curdione from Curcuma zedoaria against Gyrodactylus kobayashii in goldfish. Aquaculture. (2020) 523:735186. doi: 10.1016/j.aquaculture.2020.735186

31. Cleophas TJ, Zwinderman AH. Probit regression. In: Cleophas TJ, Zwinderman AH, editors. Machine Learning in Medicine: Part Three. Dordrecht: Springer Netherlands (2013). p. 63-8. doi: 10.1007/978-94-007-7869-6_7

32. Muller PY, Milton MN. The determination and interpretation of the therapeutic index in drug development. Nat Rev Drug Discov. (2012) 11:75161. doi: $10.1038 / \mathrm{nrd} 3801$ 
33. Kleinbaum DG, Klein M. Kaplan-meier survival curves and the logrank test. In: Kleinbaum DG, Klein M, editors. Survival Analysis: A SelfLearning Text. New York, NY: Springer New York (2012). p. 55-96. doi: 10.1007/978-1-4419-6646-9_2

34. Liu C, Wang J, Liu J, Chen G. Gradient elution reversed-phase highperformance liquid chromatography for determination of dioscin in Dioscorea hypoglauca Palibin.and Dioscorea septemloba Thunb. J Anhui Trad Chin Med College. (2013) 62:81-3. doi: 10.3969/j.issn.1000-2219.2013. 06.029

35. Tu X, Huang A, Hu Y, Ling F, Wang G. Arctigenin: an emerging candidate against infections of Gyrodactylus. Aquaculture. (2018) 495:983-91. doi: 10.1016/j.aquaculture.2018.06.064

36. Fridman S, Sinai T, Zilberg D. Efficacy of garlic based treatments against monogenean parasites infecting the guppy [Poecilia reticulata (Peters)]. Vet Parasitol. (2014) 203:51-8. doi: 10.1016/j.vetpar.2014. 02.002

37. Cable J, Harris PD. Gyrodactylid developmental biology: historical review, current status and future trends. Int J Parasitol. (2002) 32:255-80. doi: 10.1016/S0020-7519(01)00330-7
38. Hammami H, Mezghani-Jarraya R, Damak M, Ayadi A. Molluscicidal activity of various solvent extracts from Solanum nigrum var. villosum L. aerial parts against Galba truncatula. Parasite. (2011) 18:63-70. doi: 10.1051/parasite/2011181063

39. Shengwang L, Yuming W, Guangqiang Z, Shanguang Z, Shengguo J. Determination of solasodine in Solanum nigrum by TLCS. Chin Pharmaceutical J. (1997) 32:494-5.

Conflict of Interest: The authors declare that the research was conducted in the absence of any commercial or financial relationships that could be construed as a potential conflict of interest.

Copyright (C) 2021 Zhou, Dong, Liu, Yang, Xu, Yang and Ai. This is an open-access article distributed under the terms of the Creative Commons Attribution License (CC $B Y)$. The use, distribution or reproduction in other forums is permitted, provided the original author(s) and the copyright owner(s) are credited and that the original publication in this journal is cited, in accordance with accepted academic practice. No use, distribution or reproduction is permitted which does not comply with these terms. 